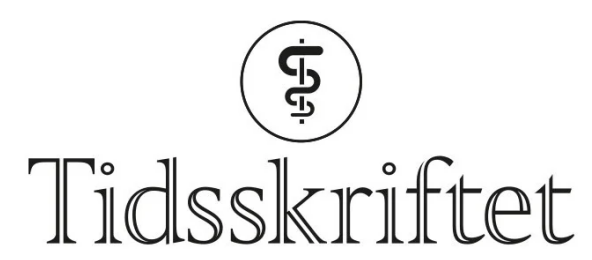

DEN NORSKE LEGEFORENING

\title{
Valproatbehandling av fertile kvinner
}

KRONIKK

\section{MARTE HELENE BJØRK}

marte.bjork@uib.no

Marte Helene Bjørk er overlege ved Nevrologisk avdeling, Haukeland universitetssjukehus og førsteamanuensis ved Universitetet i Bergen.

Forfatteren har fylt ut ICMJE-skjemaet og oppgir ingen interessekonflikter.

\section{THORSTEN ALFONS GERSTNER}

Thorsten Alfons Gerstner er dr.med., spesialist i barnesykdommer og ph.d.-stipendiat ved Regional kompetansetjeneste for barn med medfødte russkader, Sørlandet sykehus, Arendal. Forfatteren har fylt ut ICMJE-skjemaet og oppgir ingen interessekonflikter.

\section{ERIK TAUB $\varnothing L L$}

Erik Taubøll er overlege ved Nevrologisk avdeling, Oslo universitetssykehus og professor ved Universitetet i Oslo.

Forfatteren har fylt ut ICMJE-skjemaet og oppgir ingen interessekonflikter.

Fertile kvinners bruk av valproat er viktig, vanskelig og aktuelt. Medikamentet er svært fosterskadelig, men noen gravide med epilepsi blir ikke anfallsfrie uten. 


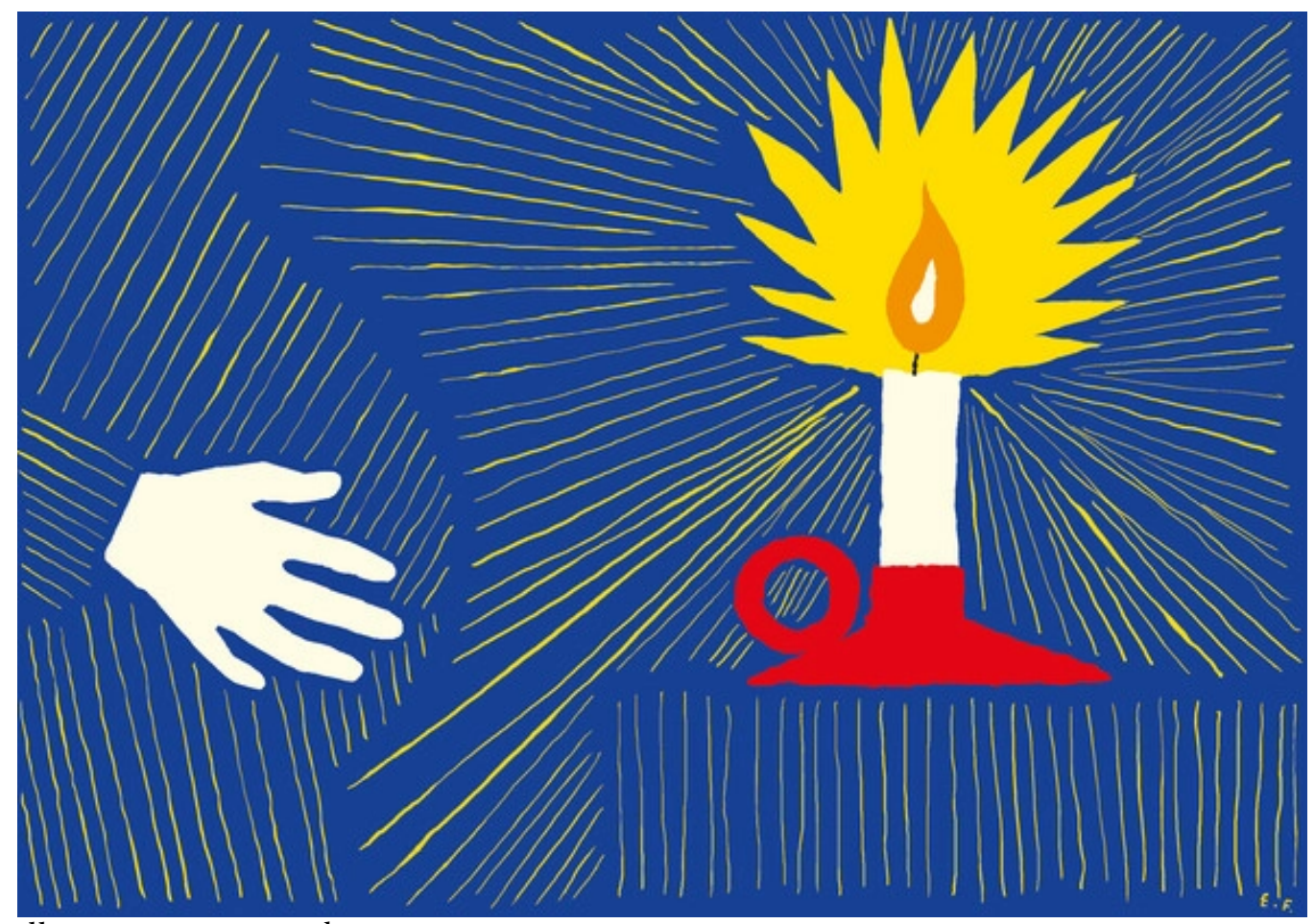

Illustrasjon: Espen Friberg

Valproat kom på markedet i Frankrike i 1967. Det er et av de mest effektive medikamentene for generalisert epilepsi, bipolar lidelse og migrene. Ettersom dette er hyppige sykdommer hos fertile kvinner, har valproat vært det tredje mest brukte antiepileptikum under graviditeten i Norden de siste 10-20 årene.

\section{Valproat og fosterutvikling}

Ett av ti barn som utsettes for valproat i graviditeten, får misdannelser som nevralrørsdefekter, hjertemisdannelser og urinveisanomalier. Dersom moren har brukt over 1 ooo-1 $500 \mathrm{mg}$ daglig, blir mer enn én av fire rammet $(\underline{1}, \underline{2})$. I 2013 fant danske forskere at barn av mødre som hadde kjøpt valproat under svangerskapet, fem ganger oftere enn andre barn fikk autismediagnose (3). Samtidig viste to store studier at barn eksponert for valproat i fosterlivet, hadde ti færre IQ-poeng enn andre (4).). Resultatene kunne ikke forklares av mors IQ eller epilepsitype og ble ikke sett ved bruk av andre epilepsimedisiner.

Valproateksponering i svangerskapet er senere assosiert med forsinket språkutvikling (5), $\operatorname{ADHD}(\underline{6})$ og dårligere skoleprestasjoner (7.). Det er uklart om det er tryggere å bruke valproat sent i graviditeten enn tidlig. Organogenesen foregår under første trimester, men kognitiv utvikling foregår fram til fødsel.

Nylig har begrepet føtal valproatspektrumlidelse (FVSD) blitt tatt i bruk for å beskrive det sammensatte kliniske bildet av misdannelser, kognitiv reduksjon, nevropsykiatriske tilstander og dysmorfe trekk som kan ses hos valproateksponerte barn (1) .

\section{Depakote-skandalen}

Grunnet funnene ovenfor publiserte legemiddelmyndighetene i Europa og Statens legemiddelverk (SLV) en advarsel mot bruk av valproat hos fertile i 2014 (므). I årene som fulgte søkte mange franske pasienter eksponert for valproat i fosterlivet, erstatning fra Sanofi. Saken ble beskrevet som en nasjonal helseskandale. I Norge uttrykte pasienter og Norsk epilepsiforbund bekymring (9.). 
Parallelt med introduksjonen av andre antiepileptika med effekt på generaliserte epilepsier, som lamotrigin og levetiracetam, har bruken av valproat hos fertile kvinner i Norge vært langsomt synkende (figur 1). Imidlertid utløste hverken advarselen fra Legemiddelverket i 2014 eller Depakote-skandalen i Frankrike noen brå nedgang i bruken av valproat.

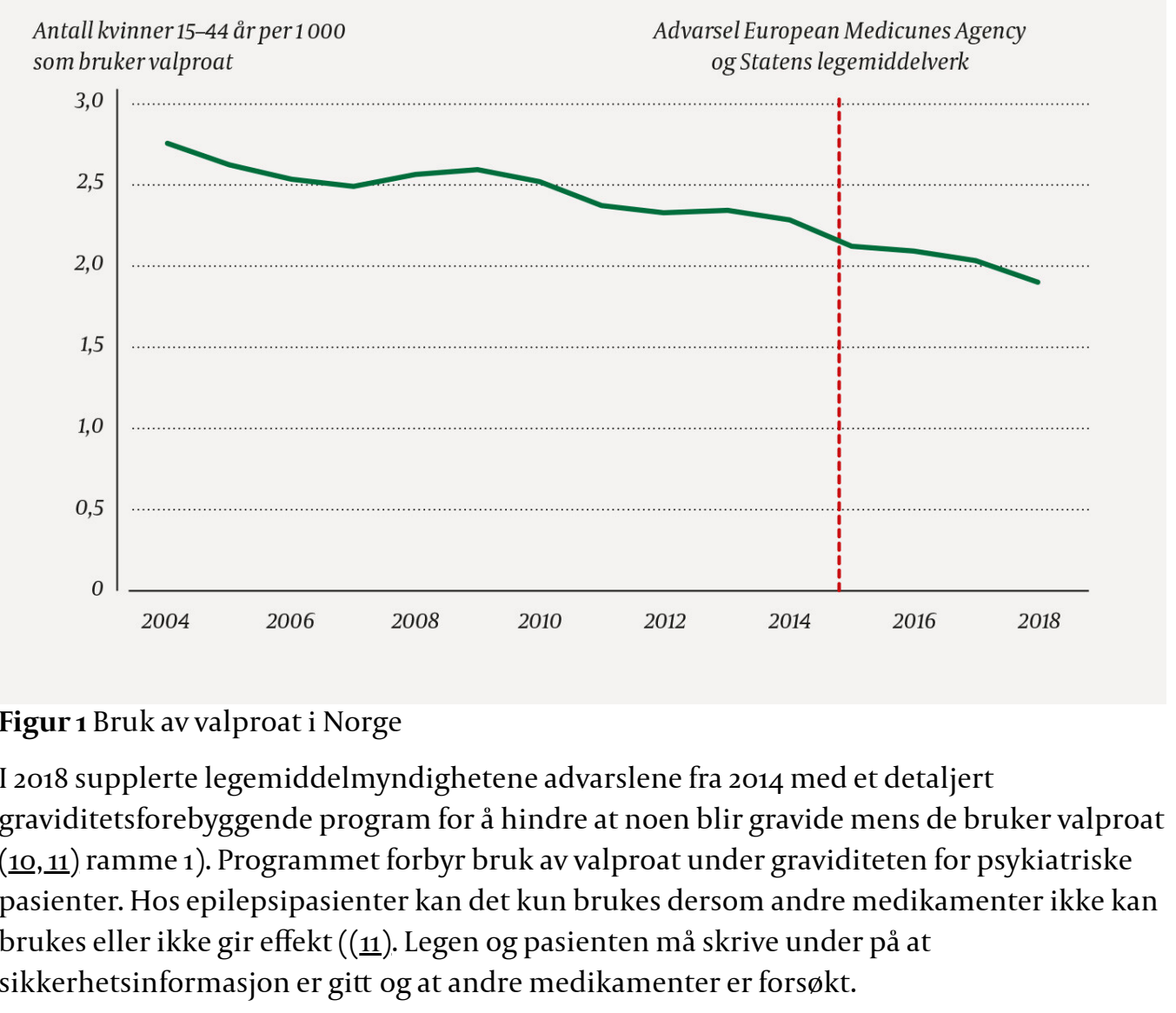

\section{Ramme 1 Felleskatalogens veiledning til helsepersonell (12)}

Kvinner med epilepsi: Valproat er kontraindisert under graviditet med mindre det ikke foreligger andre egnede alternative behandlinger. Valproat er kontraindisert hos fertile med mindre betingelsene i det gravidtetsforebyggende programmet er oppfylt.

Kvinner med bipolar lidelse: valproat er kontraindisert under graviditet. Valproat er kontraindisert hos fertile med mindre betingelsene i det gravidtetsforebyggende programmet er oppfylt.

\section{Graviditetsforebyggende program ved bruk av valproat}

Spesialist i nevrologi/psykiatri med erfaring innenfor epilepsibehandling/bipolar lidelse skal kun innlede valproatbehandling hos jenter og fertile kvinner dersom annen behandling ikke har effekt eller ikke tolereres.

Før oppstart utelukkes graviditet ved hjelp av graviditetstest tatt i blod. Svaret må bekreftes av medisinsk personale.

Spesialisten skal revurdere indikasjonen for behandling minimum årlig. 
Spesialisten skal fylle ut skjemaet om risikoen for fosterskader sammen med pasienten ved innledning av behandling, ved årlig kontroll, ved graviditetsplanlegging og ved bekreftet graviditet.

Leger som møter kvinnelige brukere av valproat skal informere

pasienten/foreldre/verge/omsorgspersoner om risikoen for fosterskade ved valproat, nødvendigheten av pålitelig prevensjonsmiddel og om å oppsøke lege ved graviditet. Informasjonen skal gis ved alle legebesøk samt besøk hos helsesøstre og jordmødre. Farmasøyter på apotek skal også informere.

Legen skal levere ut pasientveiledningen til alle kvinnelige pasienter/foreldre/verge/omsorgspersoner behandlet med valproat.

Ved ønske om svangerskap må kvinnen bytte til annen egnet behandling. For pasienter med epilepsi må spesialisten «gjøre alt for å omstille til egnet alternativ behandling» før prevensjonsmiddelet avbrytes.

Den laveste effektive dosen skal brukes, total og fri serumkonsentrasjon skal måles før, under og etter graviditet.

Kvinner eksponert for valproat under svangerskapet og deres partnere skal henvises til en spesialist med erfaring i å vurdere fosterskader av legemidler slik at de kan motta informasjon om betydningen av eksponeringen.

Ved utilsiktet graviditet skal kvinnen øyeblikkelig komme til konsultasjon og etter konsultasjonen bytte til annen egnet behandling, dersom mulig.

Betingelsene over gjelder også for seksuelt inaktive pasienter så fremt et mulig svangerskap ikke kan utelukkes.

Programmet har utløst debatt grunnet manglende nyansering og vektlegging av fertile kvinners individuelle situasjon og medisinske behov (12). Fagmiljøet i Norge har hevdet at for mange kvinner er det riktig å bruke valproat.

\section{Når er det riktig å bruke valproat hos fertile og gravide?}

Valproat er et av våre mest potente antiepileptika til bruk ved generalisert epilepsi. For denne epilepsitypen er valproat bedre enn lamotrigin og topiramat (13) og om lag like bra som levetiracetam (14.). Mange pasienter får imidlertid psykiatriske bivirkninger av levetiracetam (14.). For enkelte pasienter med generalisert epilepsi er valproat det eneste medikamentet som gir anfallsfrihet. Reduksjon i valproatdose eller medikamentbytte vil $\emptyset$ ke risikoen for anfallsforverring $(\underline{15}, \underline{16})$. Da er det nødvendig med en individuell vurdering av farene for mor og barn knyttet til anfall sett opp mot risiko for fosterskader.

Ukontrollert epilepsi kan ha livstruende konsekvenser for mor, da hyppige generaliserte krampeanfall er den viktigste risikofaktoren for plutselig uventet død ved epilepsi (SUDEP). Det er viktig at kvinner ikke blir så engstelige av advarslene mot bruk av valproat at de stopper med medikamentet eller reduserer dosen på egen hånd. I England har man siden 2013 sett en $ø$ kning i dødsfall blant gravide med epilepsi som egenhendig sluttet med antiepileptika. $4 \%$ av maternelle dødsfall i denne perioden skyldtes epilepsi. Alle kvinnene hadde ukontrollert epilepsi i svangerskapet. Åtte av ni døde av plutselig uventet død ved epilepsi, én druknet i badekaret. To av ni hadde nylig sluttet med valproat (17.).

\section{«Ukontrollert epilepsi kan ha livstruende konsekvenser for mor»}

Redusert anfallskontroll i graviditeten kan også føre til angst og uro, søvnvansker, tap av førerkort, problemer i jobb og andre sosiale vansker. 
Anfall i graviditeten er heller ikke uten betydning for fosteret. I tillegg til fysisk skade grunnet fall eller støt, kan status epilepticus gi langvarig hypoksi og i sjeldne tilfeller fosterdød (묘). Noen kliniske studier indikerer også at kortvarige generaliserte krampeanfall kan ha negative effekter som for tidlig fødsel og lav fødselsvekt (19).). En studie viste at fem eller flere generaliserte krampeanfall i graviditeten var en uavhengig

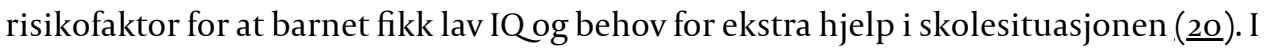

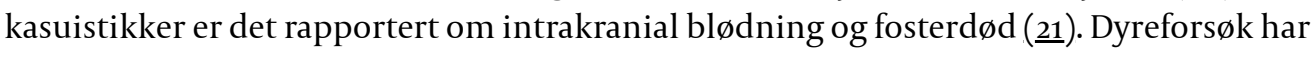
vist at avkom av rotter med hyppige generaliserte krampeanfall under graviditeten fikk dårligere vekst, problemer med motorikk og koordinasjon samt endringer i nevronale nettverk i hippocampus $(\underline{\mathbf{2 2}}, \underline{2} 3)$.

Hvorvidt det er riktig å trappe ned valproat eller bytte til annet medikament under graviditeten, vil avhenge av hvor hyppige og alvorlige anfall kvinnen har hatt før graviditet, tidligere respons på andre antiepileptika og kvinnens egne preferanser.

\section{Tilbud til barn eksponert for valproat}

Diagnostisering av barn med føtal valproatspektrumlidelse er komplisert. Diagnosen stilles klinisk og ved bruk av nevropsykologi. Kognitive og atferdsmessige utfordringer forekommer hyppig, selv om misdannelser og dysmorfe trekk er fraværende. Vanskene vil i de fleste tilfellene vedvare opp i voksen alder (1). Nevrokognitive vansker med innvirkning på verbale og auditive ferdigheter er et sentralt trekk i fenotypen til føtal valproatspektrumlidelse. I likhet med for eksempel barn med medfødte alkoholskader (FASD), stiller disse sammensatte vanskene store krav til et spesialisert og tverrfaglig helsetilbud (24).

I henhold til internasjonale anbefalinger bør barn med føtal valproatspektrumlidelse tilbys spesialisert oppfølging og behandling (1). For barn med medfødte alkoholskader finnes det et eget utredningstilbud, men ikke til barn skadet av valproat. I norske retningslinjer for epilepsibehandling anbefales det ikke spesiell oppfølging (205). Det finnes heller ikke norske retningslinjer for slik diagnostisering. Det er i tillegg utfordrende at dette er en liten gruppe som få klinikere har tilstrekkelig erfaring med. Etter vår erfaring savner familier med barn utsatt for prenatal valproateksponering et spesialisert utrednings- og oppfølgingstilbud og et sted å henvende seg. At det er mulig å bygge opp et slikt tilbud, viser erfaringene med barn med prenatal alkohol- og russkade.

\section{"Valg av medikament må vurderes individuelt for hver enkelt fertil}

kvinne med epilepsi»

Diagnostisering er viktig. Avklaring og vellykket utredning og oppfølging av disse risikopasientene i barne- og ungdomsalder vil kunne forebygge sekundære vansker i voksen alder. En klar diagnose kan også være viktig for pasientskadeerstatningssaker.

\section{Hva bør gjøres?}

Valg av medikament må vurderes individuelt for hver enkelt fertil kvinne med epilepsi. Dette bør retningslinjene åpne for.

Valproat må ikke seponeres brått når kvinnen er gravid, selv om hun er anfallsfri. Langvarig anfallsfrihet kan nettopp skyldes bruken av preparatet. Fordeler og ulemper må diskuteres grundig med pasienten. Disse kvinnene bør følges av nevrolog og fødselslege i nært samarbeid med fastlegen. Fastleger skal ikke på egen hånd la fertile kvinner starte med valproat. Det graviditetsforebyggende programmet bør forenkles slik at det er mulig å 
gjennomføre i klinisk praksis. Hensikten må være å forebygge unødvendig bruk av valproat og gi informasjon, ikke å forebygge søksmål fra eksponerte og velte ansvaret over på pasient og lege.

Videre bør Helsedirektoratet i samarbeid med fagmedisinske foreninger og pasientforeninger ta initiativ til spesialisert kompetanse og retningslinjer for utredning og oppfølging av barn som kan ha eller har føtal valproatspektrumlidelse i Norge.

\section{LITTERATUR}

1. Clayton-Smith J, Bromley R, Dean J et al. Diagnosis and management of individuals with Fetal Valproate Spectrum Disorder; a consensus statement from the European Reference Network for Congenital Malformations and Intellectual Disability. Orphanet J Rare Dis 2019; 14: 180. [PubMed] [CrossRef]

2. Tomson T, Battino D, Bonizzoni E et al. Dose-dependent teratogenicity of valproate in mono- and polytherapy: an observational study. Neurology 2015; 85: 866-72. [PubMed][CrossRef]

3. Christensen J, Grønborg TK, Sørensen MJ et al. Prenatal valproate exposure and risk of autism spectrum disorders and childhood autism. JAMA 2013; 309: 1696-703. [PubMed][CrossRef]

4. Bromley R, Weston J, Adab N et al. Treatment for epilepsy in pregnancy: neurodevelopmental outcomes in the child. Cochrane Database Syst Rev 2014; 10: CDo10236. [PubMed][CrossRef]

5. Husebye ESN, Gilhus NE, Riedel B et al. Verbal abilities in children of mothers with epilepsy: Association to maternal folate status. Neurology 2018; 91: e811-21. [PubMed][CrossRef]

6. Christensen J, Pedersen L, Sun Y et al. Association of prenatal exposure to valproate and other antiepileptic drugs with risk for attention-deficit/hyperactivity disorder in offspring. JAMA Netw Open 2019; 2: e1866o6. [PubMed][CrossRef]

7. Elkjær LS, Bech BH, Sun Y et al. Association between prenatal valproate exposure and performance on standardized language and mathematics tests in school-aged children. JAMA Neurol 2018; 75: 66371. [PubMed][CrossRef]

8. European Medicines Agency. CMDh agrees to strengthen warnings on the use of valproate medicines in women and girls 2014

https://www.ema.europa.eu/en/medicines/human/referrals/valproate-related-substances Lest 24.3.2020.

9. Vindsland S. Kan gi autisme, adhd, lavere IQ og misdannelser. Fædrelandsvennen 2016. https://www.fvn.no/nyheter/lokalt/i/E5gmA/kan-gi-autisme-adhd-lavere-iq-og-misdannelser Lest 24.3.2020.

10. European Medicines Agency. Valproate and related substances.

https://www.ema.europa.eu/en/medicines/human/referrals/valproate-related-substances-o Lest 24.3.2020.

11. Felleskatalogen. Informasjon om risiko for kvinnelige pasienter og gravide kvinner ved bruk av valproat (Orfiril, Orfiril long, Orifiril retard). Felleskatalogen. Oslo: Statens Legemiddelverk, 2018 https://www.felleskatalogen.no/medisin/dokument/valproat-veiledning-helsepersonell Lest 24.3.2020.

12. Alvestad S, Bjørnvold M, Molteberg E et al. Valproat fortsatt viktig for kvinner med generalisert epilepsi. Tidsskr Nor Legeforen 2019; 139. doi:10.4045/tidsskr.19.0220. [PubMed][CrossRef]

13. Marson AG, Al-Kharusi AM, Alwaidh M et al. The SANAD study of effectiveness of valproate, lamotrigine, or topiramate for generalised and unclassifiable epilepsy: an unblinded randomised controlled trial. Lancet 2007;369: 1016-26. [PubMed][CrossRef]

14. Tabrizi N, Zarvani A, Rezaei P et al. Levetiracetam in genetic generalized epilepsy: A prospective unblinded active-controlled trial. Epilepsy Res 2019; 157: 106214. [PubMed][CrossRef]

15. Tomson T, Battino D, Bonizzoni E et al. Withdrawal of valproic acid treatment during pregnancy and seizure outcome: Observations from EURAP. Epilepsia 2016; 57: e173-7. [PubMed][CrossRef]

16. Cerulli Irelli E, Morano A, Cocchi E et al. Doing without valproate in women of childbearing potential with idiopathic generalized epilepsy: Implications on seizure outcome. Epilepsia 2020; 61: 107-14. [PubMed][CrossRef]

17. Knight M, Nair M, Tuffnell D et al. red. Saving lives, improving mothers' care - Lessons learned to inform maternity care from the UK and Ireland Confidential Enquiries into Maternal Deaths and Morbidity 2013-15. Oxford: Epidemiology Unit, University of Oxford, 2017. 
https://www.npeu.ox.ac.uk/downloads/files/mbrrace-uk/reports/MBRRACE-

UK\%20Maternal\%20Report\%202017\%20-\%20Web.pdf Lest 24.3.2020.

18. Tomson T, Battino D, Bonizzoni E et al. Antiepileptic drugs and intrauterine death: A prospective observational study from EURAP. Neurology 2015; 85: 580-8. [PubMed][CrossRef]

19. Rauchenzauner M, Ehrensberger M, Prieschl M et al. Generalized tonic-clonic seizures and antiepileptic drugs during pregnancy-a matter of importance for the baby? J Neurol 2013; 260: 484-8. [PubMed][CrossRef]

20. Adab N, Kini U, Vinten J et al. The longer term outcome of children born to mothers with epilepsy. J Neurol Neurosurg Psychiatry 2004; 75: 1575-83. [PubMed][CrossRef]

21. Minkoff H, Schaffer RM, Delke I et al. Diagnosis of intracranial hemorrhage in utero after a maternal seizure. Obstet Gynecol 1985; 65: 22S-4S. [PubMed]

22. do Vale TG, da Silva AV, Lima DC et al. Seizures during pregnancy modify the development of hippocampal interneurons of the offspring. Epilepsy Behav 2010;19:20-5. [PubMed][CrossRef]

23. Lima DC, Vale TG, Arganãraz GA et al. Behavioral evaluation of adult rats exposed in utero to maternal epileptic seizures. Epilepsy Behav 2010; 18: 45-9. [PubMed][CrossRef]

24. Bromley RL, Baker GA, Clayton-Smith J et al. Intellectual functioning in clinically confirmed fetal valproate syndrome. Neurotoxicol Teratol 2019; 71: 16-21. [PubMed][CrossRef]

25. Kunnskapsbasert retningslinje om epilepsi. https://www.epilepsibehandling.no/ Lest 24.3.2020.

Publisert: 4. mai 2020. Tidsskr Nor Legeforen. DOI:10.4045/tidsskr.19.0767

Mottatt 24.11.2O19, første revisjon innsendt 20.3.2020, godkjent 24.3.2020.

(C) Tidsskrift for Den norske legeforening 2023. Lastet ned fra tidsskriftet.no 26. april 2023. 